\title{
Role of Diffusion Weighted Imaging in Enhancing MR Imaging in Recent Ischemic Stroke Patients
}

\author{
Hajer A. Alfadeel \\ Department of Diagnostic Radiology, Faculty of Medicine, Omer Al Mukhtar University, Al- \\ bayda, Libya.
}

Received: 20 November 2019/ Accepted: 14 August 2020

Doi: https://doi.org/10.54172/mjsc.v35i2.316

\begin{abstract}
Stroke is a common cause of admission to hospitals, and imaging in acute stroke is necessary to differentiate ischemic from haemorrhagic stroke and to exclude other diagnoses. We aimed to evaluate the role of diffusion-weighted magnetic resonance imaging (DW MRI) in the diagnosis of recent cerebral ischemic infarction in a consecutive series of patients with symptoms of acute stroke and its feasibility as first-line imaging for those patients. We report our results with DWI and apparent diffusion coefficient (ADC) mapping comparing the sensitivity of DWI with that of conventional T2 weighted and fluid-attenuated inversion recovery (FLAIR) MRI. A Prospective audit of 87 patients with clinically suspected recent stroke referred for imaging over a consecutive 20 -week period was done. The data collected included patient age, time from onset of symptoms, and clinical presentation. We performed DWI echo planar, FLAIR, turbo spin-echo T2weighted MRI, and ADC maps were generated. Conventional MR images were assessed before DW images. DWI was considered positive for the diagnosis of new arterial stroke whenever hyperintensities with reduced ADC values were observed, and the site of infarct detected on the images was included in patients' data. The results were 47 patients had a final diagnosis of recent ischemic cerebral infarct. With DWI, 98\% of the ischemic lesions were detected, whereas with FLAIR, only $70 \%$ were detected, and with T2-weighted images, $66 \%$ of lesions were found. There was a significant difference between the results of ischemic infarcts' detection on DWI and T2-w/FLAIR in relation to time from onset $(P$ value $=.012)$. In our audit, we were able to image $68 \%(60$ of 87$)$ of the referred suspected stroke patients with DW MRI within 48 hours and 39 patients (45\%) within 24 hours of the onset of symptoms. DW MRI showed high sensitivity and superiority over conventional T2 and FLAIR imaging for the detection of acute ischemic lesions in stroke patients; it also proved quite feasible as a first-line of neuroimaging.
\end{abstract}

Keywords: Diffusion Weighted Imaging; Conventional MRI; T2-Weighted; FLAIR; Stroke.

\section{INTRODUCTION}

"Stroke is characterized by a rapidly developing neurological deficit that can lead to considerable morbidity and mortality, and it is a common cause of admission to hospitals" (Tan et al., 2006). Imaging in acute stroke is necessary to differentiate haemorrhagic from ischemic stroke, as well as to identify or exclude alternate etiologies of neurological deficit such as neoplasm or extra-axial hemorrhage (Tsiouris \& Qian, 2017). In the early stage of ischemia, computed tomography (CT) is the most commonly used technique to exclude hemorrhagic stroke. However, several studies reported lower sensitivity of CT in the visualization of hyperacute ischaemic infarct in the immediate hours subsequent to onset (Chalela et al., 2007; Tan et al., 2006; Van Everdingen et al., 98). Magnetic resonance imaging (MRI) is generally thought to be better than CT for the diagnosis of acute stroke. According to Chalela et al (2007), who compared CT and MRI in emergency settings, MRI was more ac*Corresponding Author: Hajer Alfadeel hajer.alfadeel@omu.edu.ly, Diagnostic Radiology department, Omer Almukhtar University, Elbeida, Libya. 
curate than CT in the diagnosis of acute ischemia and should be the preferred test for accurate diagnosis of patients with suspected acute stroke.

Acute ischemia causes cytotoxic oedema, which makes them visible on T2-weighted (T2w) images of conventional MRI, however, this is usually not apparent in the first few hours post-ictus (Leiva-Salinas \& Wintermark, 2010). Whereas the ischemic lesion becomes hyperintense on diffusion-weighted imaging (DWI) relative to normal tissue within minutes of injury in experimental models and within few hours of stroke onset in patients as the infarct appearance is influenced mainly by the apparent diffusion coefficient (ADC) and T2 relaxation time of the tissue (Rivers et al., 2006). The ADC, a measure of the freedom of water diffusion, is believed to be low because of a shift of water, within hypoxic brain parenchyma, from the extracellular to the intracellular compartment, where water diffusion is relatively restricted (Lansberg et al., 2001).

This low ADC is responsible for the high signal of the acute ischemic infarct on DWI. The ADC maps are generated by mathematically eliminating the T2-w images from the DWI, they can be used to determine whether hyperintensity on DWI represents a true reduction of diffusion, which appears dark on ADC map, or T2 shine-through, a later effect in stroke causing high signal on DWI and ADC map due to T2 hyperintensity. (Allen et al., 2012; Maas \& Mukherjee, 2005).

We report our results with DWI, including the ADC mapping. The purpose of this study is to determine the role of DWI in the diagnosis of recent cerebral ischaemic infarction in a consecutive series of patients with symptoms of acute stroke, in order to demonstrate it we compared the sensitivity of DWI with that of T2-w and Fluid-attenuated inversion recovery (FLAIR) sequences. We did not include a time limitation in this study. Moreover, we evaluated the feasibility of DWI as a first line neu- roimaging for suspected recent stroke patients.

\section{MATERIALS AND METHODS}

A single-center prospective study was carried out in a consecutive series of patients. It took place from Sept 30, 2013, to Feb 25, 2014, at Alteba imaging center in Elbeida city in Libya, the only imaging center in the region with $\mathrm{CT}$ and MRI scanners at the time. Over a 5-month period, ninety patients underwent MRI. These patients were referred with complaints of focal neurological deficit, hemiparesis/hemiplegia and other clinical findings consistent with stroke. The time of stroke onset was determined to be the time at which the patient was last known to be symptom-free.

All patients were studied on a 1.5 Tesla MR Scanner (Intera 11, R10.6 Philips, Netherlands). The conventional scanning protocol of the MR examination included axial $6 \mathrm{~mm}$ thick T1 weighted (TR/TE- 550/15) spin-echo sequence, an axial $6 \mathrm{~mm}$ thick TSE /T2 weighted sequence $(550 / 110)$ and an axial $6 \mathrm{~mm}$ thick FLAIR sequence (TR/ effective TE- 800/120, TI- $2000 \mathrm{msec}$ ). For DWI, a single shot spinecho/echoplanar imaging sequence was obtained. Acquisition parameters included 10,000/92 TR/TE, single excitation, $25 \mathrm{~cm}$ FOV, 112X112 matrix, and a 5mm section thickness with a $1 \mathrm{~mm}$ interslice gap. Gradient strength corresponding to $\mathrm{b}$ values (diffusion sensitivities) of 0 and 1000 second $/ \mathrm{mm} 2$ were used. Twenty-Two axial images covering the entire brain were obtained. Apparent diffusion coefficient (ADC) maps were also calculated from T2-weighted and diffusion-weighted echoplanar images.

The conventional MR sequences and DWI images were reviewed in conjunction with relevant clinical history. Signal intensity abnormalities noted on T2-w, FLAIR, and DWI images were compared. Initial DWI was considered positive for the diagnosis of new arterial stroke whenever hyperintensities with reduced ADC values were observed. Old lesions were defined 
as lesions seen on FLAIR without corresponding DWI abnormality or as a DWI hyperintensity without a corresponding reduction in ADC ("T2 shine through"). We classified infarcts using the classification from Allen et al. (2010) according to the time from onset of symptoms into hyperacute (from 0 to 24 hours (h)), acute (24h to 7 days) and subacute ( 7 days to 3 weeks).

For statistical data analysis we used the SPSS software package, a one-way ANOVA test was performed to determine if the study results were statistically significant i.e. $P$ value less than 0.05 , then the cross tabulation method was performed to determine exactly which of the MRI sequences (DWI, FLAIR, and T2-w) had a significant difference.

\section{RESULTS}

Altogether 90 consecutive patients over a period of 20 weeks initially fulfilled the criteria for inclusion into the audit. However, three patients had not undergone DWI in their MRI examinations. We therefore reviewed the results of 87 patients (54 women, 33 men; median age 65 years; range, 29 to 93 years) with symptoms and signs of a recent stroke. Before the current ischemic event, 16 patients (18\%) had suffered from previous ischemic events. The mean time between the onset of symptoms and the MR investigations was 63 hours (range, 3 hours to 14 days). 39 out of 87 patients $(45 \%)$ were imaged in the hyperacute stage $(<24$ hours after onset), 39 patients $(45 \%)$ imaged in acute stage between 24 hours and 7 days after onset (54\% of them imaged between 24 and 48h), nine patients (10\%) were imaged between 7 and 14 days after onset of symptoms.

A diagnosis of recent ischemic infarct was made in 47 (54\%) patients. Their demographic data and presenting clinical symptoms and infarct sites are shown in Table 1. Other diagnoses were old ischaemia in $12(14 \%)$ patients, haemorrhage in 6 patients, neoplasm in 3 patients, encephalitis, demyelination in 2 patients, and normal in $17(20 \%)$ patients. 
Table:(1). Demographic Data, Clinical Symptoms, and Infarct Location on MRI Scan

\begin{tabular}{|c|c|c|c|c|c|c|c|}
\hline Patient & Sex & Age & Complaint & Paresis & Lesion location & Side & Artery \\
\hline 1 & $\mathrm{~F}$ & 90 & $\mathrm{HA}+\mathrm{HP}$ & $a, 1$ & $\mathrm{C}+\mathrm{SC}$ & $\mathrm{L}$ & PCA \\
\hline 2 & $\mathrm{~F}$ & 70 & $\mathrm{HA}+\mathrm{HP}$ & $\mathrm{a}, 1$ & $\mathrm{C}+\mathrm{SC}$ & $\mathrm{R}$ & PCA \\
\hline 3 & $\mathrm{~F}$ & 60 & $\mathrm{HP}$ & $\mathrm{a}, 1$ & $\mathrm{C}+\mathrm{SC}$ & $\mathrm{R}$ & WS ACA-MCA \\
\hline 4 & $\mathrm{~F}$ & 67 & Vertigo, ataxia & & Cerebellar & $\mathrm{R}$ & PICA \\
\hline 5 & M & 48 & $\mathrm{HP}+\mathrm{PHA}$ & $\mathrm{a}, 1$ & $\mathrm{C}+\mathrm{SC}$ & $\mathrm{L}$ & MCA \\
\hline 6 & $\mathrm{~F}$ & 47 & Coma & & Posterior circulation & & Basilar \\
\hline 7 & $\mathrm{~F}$ & 80 & HP & $\mathrm{a}, 1$ & $\mathrm{C}+\mathrm{SC}$, Thalamus & $\mathrm{R}$ & PCA \\
\hline 8 & $\mathrm{M}$ & 60 & HPL+ PHA & $\mathrm{a}, 1, \mathrm{f}, \mathrm{s}$ & $\mathrm{C}+\mathrm{SC}+\mathrm{BG}$ & $\mathrm{R}$ & MCA \\
\hline 9 & $\mathrm{~F}$ & 88 & HP & $\mathrm{a}, \mathrm{l}$ & $\mathrm{C}+\mathrm{SC}$ & $\mathrm{R}$ & WS MCA-PCA \\
\hline 10 & M & 70 & НP & $\mathrm{a}, \mathrm{s}$ & $\mathrm{C}+\mathrm{SC}$ & $\mathrm{L}$ & ACA \\
\hline 11 & $\mathrm{~F}$ & 93 & HP & $\mathrm{a}, \mathrm{l}, \mathrm{f}, \mathrm{s}$ & BG & $\mathrm{R}$ & LSA \\
\hline 12 & $\mathrm{~F}$ & 67 & $\mathrm{HP}+\mathrm{PHA}$ & $\mathrm{F}$ & $\mathrm{C}+\mathrm{SC}$ & $\mathrm{L}$ & $\mathrm{MCA}$ \\
\hline 13 & $\mathrm{~F}$ & 85 & $\mathrm{HP}+\mathrm{PHA}$ & $\mathrm{a}, \mathrm{l}, \mathrm{f}, \mathrm{s}$ & $\mathrm{C}+\mathrm{SC}+\mathrm{CN}$ & $\mathrm{R}$ & MCA \\
\hline 14 & $\mathrm{M}$ & 64 & PHA & $\ldots$ & Corona radiate & $\mathrm{R}$ & WS LSA-MCA \\
\hline 15 & $\mathrm{~F}$ & 70 & HP & $\mathrm{a}, \mathrm{l}, \mathrm{f}, \mathrm{s}$ & $\mathrm{C}+\mathrm{SC}$ & $\mathrm{R}$ & $\mathrm{MCA}$ \\
\hline 16 & M & 60 & HP & $a, 1$ & Cerebellar, Pons, midbrain & $\mathrm{L}$ & SCA, PCA \\
\hline 17 & M & 65 & HA & $\ldots$ & $\mathrm{C}+\mathrm{SC}$ & $\mathrm{R}$ & WS ACA-MCA-PCA \\
\hline 18 & M & 82 & HP & $\mathrm{a}, 1, \mathrm{f}$ & $\mathrm{C}+\mathrm{SC}$, Thalamus & $\mathrm{L}$ & PCA \\
\hline 19 & $\mathrm{~F}$ & 70 & $\mathrm{HPL}+\mathrm{PHA}$ & $\mathrm{a}, \mathrm{l}, \mathrm{f}, \mathrm{s}$ & $\mathrm{C}+\mathrm{SC}$ & $\mathrm{L}$ & MCA \\
\hline 20 & $\mathrm{~F}$ & 70 & HPL+PHA & $\mathrm{a}, 1, \mathrm{f}, \mathrm{s}$ & $\mathrm{C}+\mathrm{SC}$ & $\mathrm{R}$ & MCA \\
\hline 21 & M & 93 & Confusion & $\ldots$ & Cerebellar & $\mathrm{L}$ & PICA \\
\hline 22 & $\mathrm{~F}$ & 80 & HP+PHA & $\mathrm{a}, 1, \mathrm{f}$ & Corona radiate & $\mathrm{R}$ & Deep MCA \\
\hline 23 & $\mathrm{~F}$ & 90 & $\mathrm{PHA}+\mathrm{HP}$ & $\mathrm{a}, \mathrm{l}, \mathrm{f}, \mathrm{s}$ & $\mathrm{C}+\mathrm{SC}+\mathrm{BG}$ & $\mathrm{R}$ & $\mathrm{MCA}$ \\
\hline 24 & $\mathrm{~F}$ & 62 & HP+HA & $\mathrm{a}, \mathrm{l}, \mathrm{s}$ & $\mathrm{C}+\mathrm{SC}$ & $\mathrm{L} / \mathrm{R}$ & PCA \\
\hline 25 & M & 62 & $\mathrm{HP}$ & $\mathrm{a}, 1, \mathrm{f}$ & $\mathrm{C}+\mathrm{SC}$ & $\mathrm{R}$ & MCA \\
\hline 26 & M & 70 & HР & $\mathrm{a}, 1, \mathrm{f}$ & $\mathrm{C}+\mathrm{SC}$ & $\mathrm{L}$ & MCA \\
\hline 27 & $\mathrm{~F}$ & 65 & $\mathrm{HP}$ & $\mathrm{a}, \mathrm{f}$ & Corona radiate & $\mathrm{L}$ & Deep MCA \\
\hline 28 & M & 70 & Confusion & $\ldots$ & Cerebellar & $\mathrm{L}$ & PICA \\
\hline 29 & $\mathrm{~F}$ & 60 & HP+PHA & $a, f$ & $\mathrm{C}+\mathrm{SC}$ & $\mathrm{L}$ & WS MCA--PCA \\
\hline 30 & $\mathrm{M}$ & 65 & $\mathrm{HP}$ & $\mathrm{a}, 1$ & BG & $\mathrm{R}$ & LSA \\
\hline 31 & M & 44 & HP & $\mathrm{a}, 1$ & Lacunar & $\mathrm{R}$ & TGA \\
\hline 32 & $\mathrm{~F}$ & 65 & HP & $a, f$ & Lacunar & $\mathrm{L}$ & WS ACA-MCA \\
\hline 33 & $\mathrm{M}$ & 75 & HP & $\mathrm{a}, 1$ & Lacunar & $\mathrm{R}$ & AchA \\
\hline 34 & $\mathrm{~F}$ & 85 & HPL+ PHA & $\mathrm{a}, \mathrm{l}, \mathrm{f}, \mathrm{s}$ & $\mathrm{C}+\mathrm{SC}+\mathrm{BG}$ & $\mathrm{L}$ & MCA \\
\hline 35 & $\mathrm{~F}$ & 50 & HP & $\mathrm{a}, 1$ & Corona radiate & $\mathrm{R}$ & Deep MCA \\
\hline 36 & $\mathrm{~F}$ & 80 & HP & $\mathrm{a}, 1$ & $\mathrm{C}, \mathrm{SC}$ & $\mathrm{R}$ & PCA \\
\hline 37 & $\mathrm{~F}$ & 80 & HP & $\mathrm{a}, 1, \mathrm{~s}$ & $\mathrm{C}+\mathrm{SC}$ & $\mathrm{L}$ & MCA \\
\hline 38 & M & 57 & HP & $\mathrm{a}, 1, \mathrm{f}$ & Lacunar & $\mathrm{L}$ & AchA \\
\hline 39 & M & 65 & $\mathrm{HP}+\mathrm{PHA}$ & $\mathrm{a}, 1$ & Pons & $\mathrm{R}$ & BA branch \\
\hline 40 & $\mathrm{~F}$ & 65 & HPL & $\mathrm{a}, 1$ & Corona radiate & $\mathrm{L}$ & WS ACA-MCA \\
\hline 41 & M & 55 & $\mathrm{HP}+\mathrm{PHA}$ & $\mathrm{a}, 1, \mathrm{f}$ & Semiovale, Corona & $\mathrm{R}$ & WS MCA-MCA \\
\hline 42 & M & 73 & $\mathrm{HP}+\mathrm{HA}$ & $\mathrm{a}, 1$ & $\mathrm{C}+\mathrm{SC}$ & $\mathrm{L}$ & PCA \\
\hline 43 & $\mathrm{~F}$ & 65 & HP & $\mathrm{a}, \mathrm{l}, \mathrm{f}, \mathrm{s}$ & BG & $\mathrm{R}$ & LSA \\
\hline 44 & $\mathrm{~F}$ & 86 & $\mathrm{HP}+\mathrm{PHA}$ & $\mathrm{a}, 1, \mathrm{f}$ & $\mathrm{C}+\mathrm{SC}$ & $\mathrm{R}$ & $\mathrm{MCA}$ \\
\hline 45 & $\mathrm{~F}$ & 65 & HP & $\mathrm{a}, 1, \mathrm{f}$ & $\mathrm{C}+\mathrm{SC}$, Thalamus & $\mathrm{L}$ & PCA \\
\hline 46 & $\mathrm{~F}$ & 82 & Coma & $\ldots$ & Post circulation & & Basilar \\
\hline 47 & M & 53 & HP & $a, f$ & $\mathrm{C}, \mathrm{SC}$ & $\mathrm{L}$ & ACA \\
\hline
\end{tabular}

PHA indicates dysphasia/aphasia. HP, hemiparesis. HPL, hemiparalysis. HA, hemianopia; a, arm; l, leg. f, face; s, hemisensory loss. C, cortical; SC, subcortical; CN, caudate nucleus; BG, basal ganglia, L, left hemisphere; R, right hemisphere; TGA, thalamogeniculate artery; MCA, middle cerebral artery; AChA, anterior choroidal artery; ACA, anterior cerebral artery; LSA, lateral lenticulostriate artery; WS, watershed infarct; PCA, posterior cerebral artery; and BA, basilar artery. Note. The abbreviatios are from "Diffusion-Weighted Magnetic Resonance Imaging in Acute Stroke", by K. J. Van Everdingen et al, 1998, stroke, 2 
Overall, of the 47 patients (19 men, 28 women; mean age, 69 years; range, 44 to 93 years) with recent ischemic stroke, DWI clearly identified ischemic lesions in 46 patients $(98 \%)$ as compared with 33 patients $(70 \%)$ and 31 patients $(66 \%)$ in whom ischemic lesions were detected on FLAIR and T2-w images respectively, see figure1 for illustration.

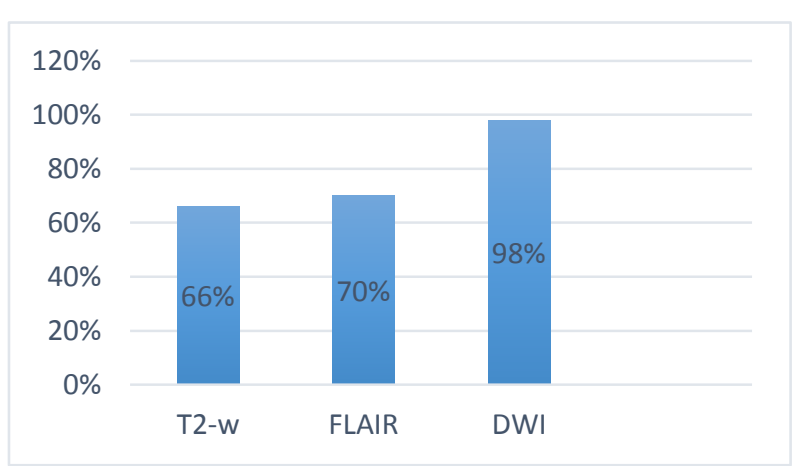

Figure (1). Graph compares the percentage of patients with recent ischemic lesions on DWI and T2-w and FLAIR sequences.

The results for the detection of ischemic lesions with different time onset on T2-w, FLAIR, and DWI scans are summarized in Table 2.

Table:(2). Number (and Percentage) of Ischemic Lesions Detected on T2-w, FLAIR, and DWI Scans.

\begin{tabular}{|c|c|c|c|c|c|c|}
\hline & \multirow{2}{*}{$\begin{array}{l}\text { All } \\
\text { lesions }\end{array}$} & \multicolumn{5}{|c|}{ Time Between Onset and MRI in hour } \\
\hline & & $0-6$ & $6-16$ & $16-24$ & $24-168$ & $168-336$ \\
\hline $\mathrm{T} 2-\mathrm{w}$ & $\begin{array}{l}31 / 47 \\
(66 \%)\end{array}$ & $\begin{array}{c}0 / 5 \\
(0 \%)\end{array}$ & $\begin{array}{l}5 / 10 \\
(50 \%)\end{array}$ & $\begin{array}{l}12 / 13 \\
(92 \%)\end{array}$ & $\begin{array}{l}9 / 14 \\
(64 \%)\end{array}$ & $\begin{array}{c}5 / 5 \\
(100 \%)\end{array}$ \\
\hline FLAIR & $\begin{array}{l}33 / 47 \\
(70 \%)\end{array}$ & $\begin{array}{c}0 / 5 \\
(0 \%)\end{array}$ & $\begin{array}{l}7 / 10 \\
(70 \%)\end{array}$ & $\begin{array}{l}12 / 13 \\
(92 \%)\end{array}$ & $\begin{array}{l}9 / 14 \\
(64 \%)\end{array}$ & $\begin{array}{c}5 / 5 \\
(100 \%)\end{array}$ \\
\hline DWI & $\begin{array}{l}46 / 47 \\
(98 \%)\end{array}$ & $\begin{array}{l}5 / 5 \\
(100 \%)\end{array}$ & $\begin{array}{l}10 / 10 \\
(100 \%)\end{array}$ & $\begin{array}{l}13 / 13 \\
(100 \%)\end{array}$ & $\begin{array}{l}14 / 14 \\
(100 \%)\end{array}$ & $\begin{array}{c}4 / 5 \\
(98 \%)\end{array}$ \\
\hline
\end{tabular}

Values are number (percentage) of ischemic lesions detected. Lesions are grouped according to the time between the onset of symptoms and the MRI investigation

The one-way ANOVA test and cross-tabulation method analysis of the results in relation to time from onset revealed that there is a statically significant difference between DWI and T2W/FLAIR in the detection of ischemic infarcts $(P$ value $=.012)$. See tables 3,4 .
Table:(3). ANOVA test correlation of ischemic infarct detection versus Time between onset and MRI in hours

\begin{tabular}{llllll}
\hline \hline & $\begin{array}{l}\text { Sum of } \\
\text { Squares }\end{array}$ & Df & $\begin{array}{l}\text { Mean } \\
\text { Square }\end{array}$ & F & Sig. \\
\hline $\begin{array}{l}\text { Between } \\
\text { Groups }\end{array}$ & 14.413 & 3 & 4.804 & 4.099 & .012 \\
$\begin{array}{l}\text { Within } \\
\text { Groups } \\
\text { Total }\end{array}$ & 50.395 & 43 & 1.172 & & \\
\hline \hline
\end{tabular}

Table:(4). Ischemic infarct found on DWI, T2 and FLAIR versus Time between onset and MRI in hours Cross tabulation

\begin{tabular}{lllllll}
\hline \hline & \multicolumn{5}{c}{ Time between onset and MRI } \\
\cline { 2 - 6 } $\begin{array}{l}\text { Count of ischemic } \\
\text { infarct found on }\end{array}$ & $0-$ & $6-$ & $16-$ & $24-$ & $168-$ & Total \\
& 6 & 16 & 24 & 168 & 336 & \\
\hline DWI & 5 & 3 & 1 & 5 & & 14 \\
DWI+FLAIR+T2- & & 5 & 12 & 9 & 4 & 30 \\
W & & 2 & & & & 2 \\
DWI+FLAIR & & & & & 1 & 1 \\
$\begin{array}{l}\text { FLAIR+T2-w } \\
\text { Total }\end{array}$ & 5 & 10 & 13 & 14 & 5 & 47 \\
\hline \hline
\end{tabular}

T2-w and FLAIR failed to diagnose recent ischemic infarcts (falsely negative) in 16 and 14 patients respectively. Ischemic lesions were absent on T2-w and FLAIR in all stroke patients imaged within 6 hours from onset of symptoms and were only detected on DWI, see example in figure 2. Nine patients imaged after six-hour onset, who were positive for infarct on DWI, had false-negative findings on both $\mathrm{T} 2-\mathrm{w}$ and FLAIR (four patients imaged in 6-24 h, five patients imaged in 24-168 $\mathrm{h}$ from onset of symptoms), all of them had had small or lacunar infarcts (See figures 3, 4, 5, 6). They were missed due to: 1) - nonspecific periventricular white matter hyperintensities in two patients. 2) - adjacent chronic infarct in three patients. 3) multiple different age lacunar infarcts in three patients. 4-very small (one patient). Only in retrospect after viewing the DWI/ADC images some of the missed acute lacunar ischemic lesions could be seen on T2 and FLAIR.

T2-w and FLAIR results were only different in two patients imaged at $12 \mathrm{~h}$ and $15 \mathrm{~h}$ from onset. FLAIR and DWI clearly detected the ischemic lesions that were not seen on $\mathrm{T} 2-\mathrm{w}$ in these two cases (patients 38 and 39 in table 1), one had pontine infarct, and the other had posterior limb internal capsule infarct. 
DWI missed recent ischemic damage (i.e. was falsely negative) in only one patient, who was examined 7 days after stroke onset and had a lacunar infarct (patient 32). The lesion appeared hyperintense on T2-w and FLAIR images, less conspicuous on DWI with a normal signal on ADC map.

No false-positive lesions were found with DWI when combined with T2-w.

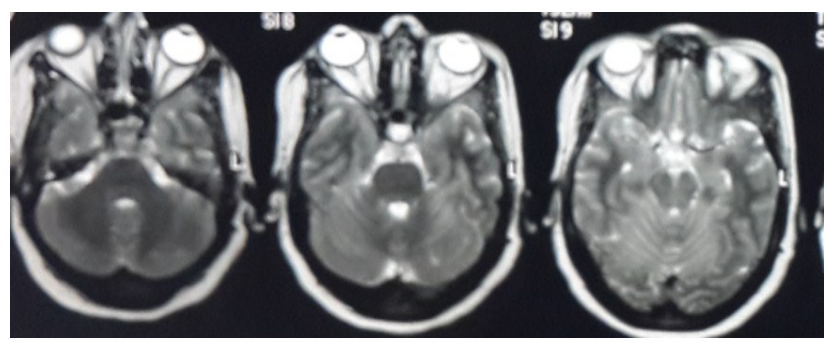

a

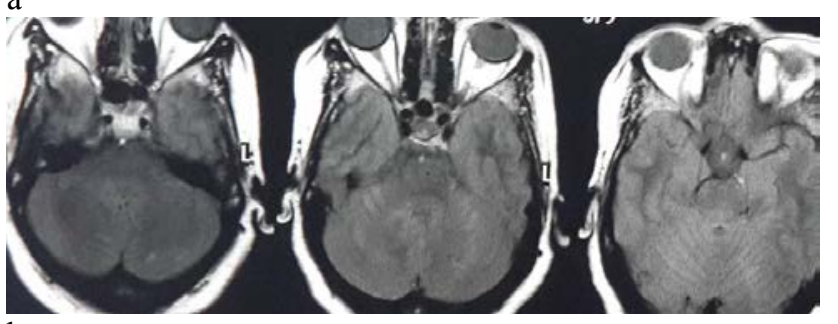

b

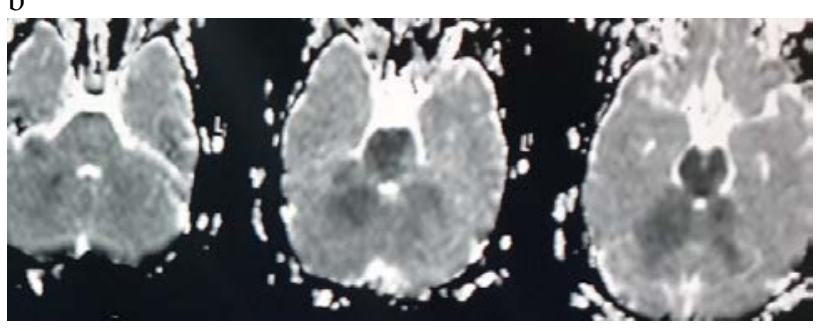

$\mathrm{C}$

Figure (2). Forty-seven-year-old woman with an acute coma state, starting less than 6 hours before MRI examination (patient 6). On the early T2-w (a) and FLAIR (b) images, no ischemic lesion was visible, the early DWI (not shown) shows hyperintensity in the posterior circulation territory, which can be appreciated as a hypointensity on the ADC trace map (c). In retrospect, loss of signal void of basilar artery (Hyperintense vessel sign) can be appreciated on FLAIR (b) which is indicative of slow blood flow distal to the site of acute arterial obstruction.

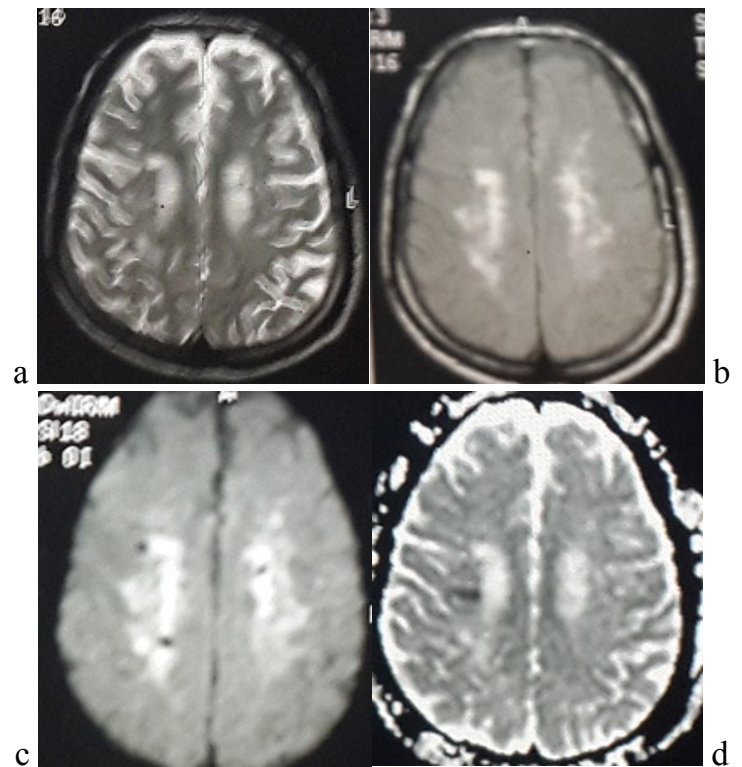

Figure (3). Sixty-four-year-old man with an acute slurred speech 7 hours before MRI examination (patient 14). The right parietal deep WS-infarct was not recognized on T2-w (a) and FLAIR (b) images because of numerous $\mathrm{T} 2$ hyperintense deep white matter lesions representing small vessel ischaemic changes. DWI scan (c) shows the same hyperintensity as FLAIR, one of which can be appreciated as a hypointensity on the ADC trace map (image $\mathrm{d}$ ) representing acute infarct.

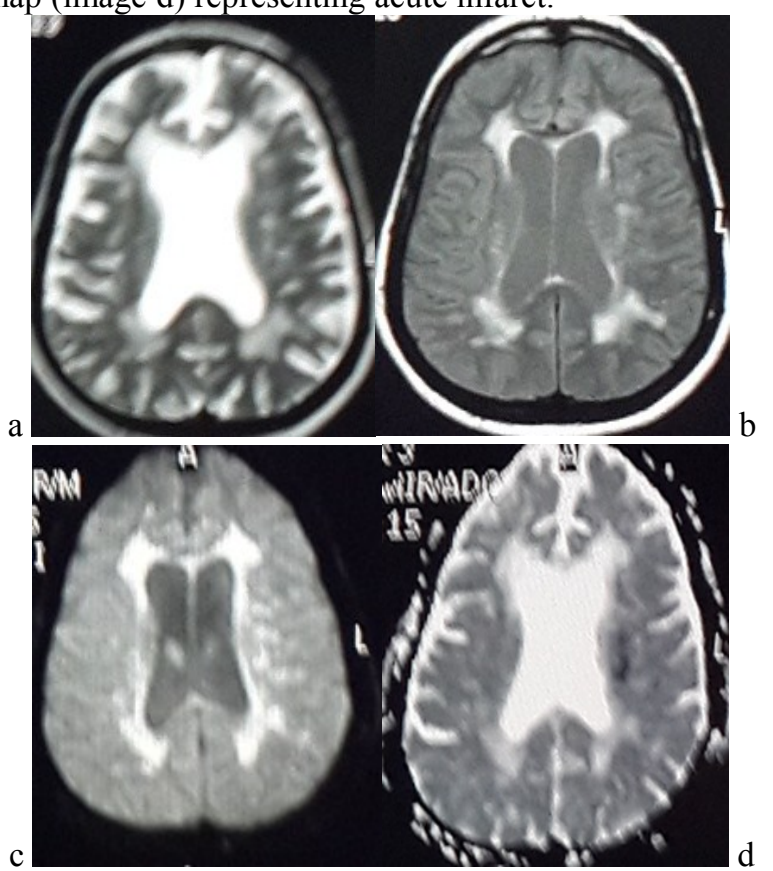

Figure (4). Sixty-five-year-old women with an acute mouth deviation 15 hours before MRI examination (patient 27). There are discrete and confluent patchy deep white matter T2 hyperintensties with left parietal acute ischaemic lacunar infarct appreciated as a hypointensity on the ADC trace map (d), on T2-w (a) and FLAIR (b) images, the lesion would have gone undetected. 


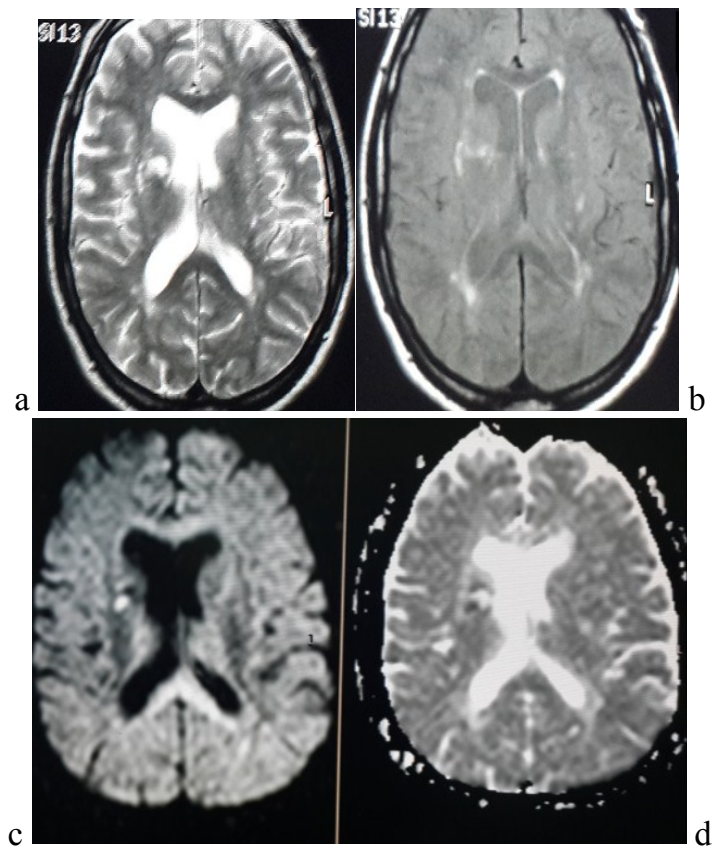

Figure 5. Sixty-five-year-old man with new onset leftsided hemiparesis 22 hours before MRI examination (patient 43). On T2-w (a) and FLAIR (b) images, no recent ischemic lesion was visible, only old lacunar ischaemic infarction at right basal ganglia. DWI scan (c) shows a right-sided hyperintensity in the lentiform nucleus, which can be appreciated as a hypointensity on the ADC trace map (d) indicating a new lacunar infarct.

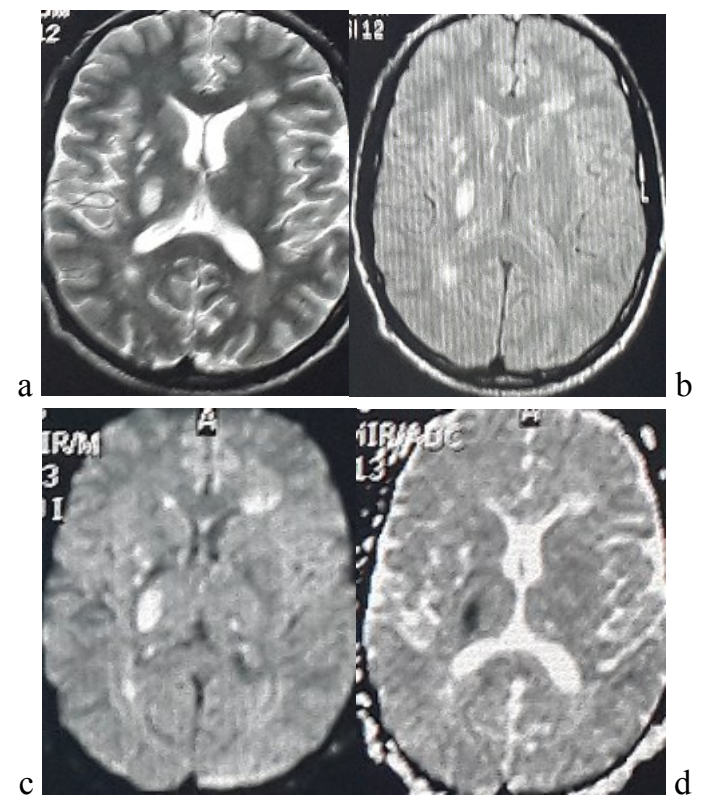

Figure 6. 44-year-old man with acute left-sided hemiparesis around 72 hours before an MRI examination (patient 31). T2, FLAIR, DWI images ( $a, b$, c respectively) revealed multiple lacunar hyperintense lesions at the right thalamus and right lentiform nucleus and left frontoparietal periventricular white matter. The ADC map (d) depicted the right thalamic infarct to be the most recent one as it appeared hypointense.
DWI detected ischemic infarcts with haemorrhagic transformation in two patients (imaged after 24 hours from onset), T2 and FLAIR depicted high signal around the hemorrhage, which can be caused by oedema, surrounding a primary intra-axial hemorrhage. DWI showed a high signal at the margin of the haemorrhage with corresponding low signal on ADC map indicating ischemia with haemorrhagic transformation rather than primary haemorrhage.

\section{DISCUSSION}

This study was designed to assess the sensitivity of DW MRI for the detection of recent ischemic infarct over conventional MRI and its accessibility as the first line of imaging. Our sample was representative of a range of patients with a clinical suspicion of recent stroke who are likely to present for imaging at different times from onset of symptoms (a few hours to 2 weeks). We considered the design of no time limit in our study to be clinically relevant, as patients with stroke-like symptoms will be referred for imaging as the initial step in management irrespective of time from onset. We evaluated T2-w images first, FLAIR second and DWI/ADC last because typically DWI is added to conventional MRI rather than done separately.

Our results confirm that DWI is the most useful imaging sequence in the diagnosis of recent ischemic stroke. All infarcts except one were detected on DWI, whereas with T2-w, FLAIR imaging, $34 \%$, and $30 \%$ of lesions respectively were not detected. The sensitivity of DWI for hyperacute ( 0 - $24 \mathrm{~h}$ from onset) and acute (24h7 days) ischemic strokes was $100 \%$. Our findings are in agreement with several other previously reported studies regarding the diagnostic yield of DWI, which reported high sensitivity of DWI ranging from 91 to $100 \%$ (Fiebach et al., 2002; Gonzales et al., 1999; Lansberg et al., 2000).

Early DWI detected ischemic lesions in all positive stroke patients imaged within $6 \mathrm{~h}$ from onset of ischemic symptoms before any chang- 
es were evident on conventional MRI. This supports previous reports that a mismatch between positive DWI and negative FLAIR suggests that the stroke occurred at least less than $6 \mathrm{~h}$ beforehand (Huisa et al., 2012; LeivaSalinas \& Wintermark, 2010).

The inclusion of ADC maps increased the confidence in the interpretation of DWI with the characteristic appearance of acute ischemic lesions as bright on DWI sequences and dark on ADC maps. DWI/ADC sequences were able to not only confirm the diagnosis of suspected ischemic infarct but also determine the age of the infarct, which is of clinical importance to the patient. The relative ADC remained low in all acute infarcts up to several days from onset. It progressively increased to be pseudonormalized on ADC map at around day seven, which resulted in one patient being missed on DWI. The ADC value elevated after day 7 resulting in high signal on both DWI and ADC map. In a serial study by Lansberg et al. (2001) of 27 patients with acute strokes, a low ADC value indicated, with good sensitivity (88\%), and specificity $(90 \%)$, that a lesion was less than 10 days old.

In general, acute ischemic lesions with characteristic wedge-shaped cortical and subcortical high signal change confined to a vascular territory, with or without an associated mass effect, are well appreciated on conventional T2-w and FLAIR MR Images. However, this is not the case for small or lacunar lesions, especially with preexisting white matter changes and/or chronic ischemic infarct. On T2, they have similar signal intensity making the delineation of the more recent ischemic damage difficult and easily missed by the observer (Augustin et al., 2000). "Diffusion imaging aids in the identification of areas of acute ischemic injury against the backdrop of diffuse nonspecific T2-w signal abnormalities that are often seen in elderly patients, or when infarcts of different ages coexist" (Maas \& Mukherjee, 2005).
In our study, the combined use of DWI, conventional T2-w, and FLAIR sequences improved the diagnostic information in 30 patients $(64 \% ; P=.012)$ of all MR examinations. DWI was superior to conventional imaging in 14 patients $(30 \%)$. In nine of them, DWI discriminated new lacunar infarcts from small vessel ischemic white matter changes, older lacunar infarcts, or an adjacent chronic infarct. The signal characteristics of acute infarcts on DWI (bright on DWI, low on ADC map) made them easily separable despite small size from older hyperintensities, thus greatly contributing to the detection of acute lacunar infarcts that would have been missed on T2-w and FLAIR images.

Our experience confirms the findings reported by Choi et al. (2000) in their study about DWI in vascular dementia patients, which concluded that new foci of altered signal intensity were only distinguishable from prior injuries with DWI and not conventional MRI.

We are aware of only one study in the literature that compared DWI and conventional MRI in a consecutive series of patients with suspected recent cerebral ischemia and an interval between onset of clinical symptoms and MR imaging of 1 to 14 days (Augustin et al., 2000). The results of our study were similar to their results. In Augustin et al. (2000) study, 62\% of ischemic lesions among 53 patients were identified or suspected on conventional T2-w images (66\% in our study), DWI (same as in our study) was falsely negative in only one patient, who was examined 8 days after stroke and had small subcortical lesions. Overall, in Augustin et al. (2000) study DWI provided information not accessible with T2-weighted imaging in 15 patients $(28 \%)$ (comparable to 14 patients $(30 \%)$ in our study), and was more likely to make a diagnostic contribution in the first week of stroke and in patients with small lesions or preexisting ischemic cerebral damage than conventional MR imaging, which is in keeping with the findings of our study. 
Furthermore, our findings showed that the DWI was useful in differentiation between primary intracerebral haemorrhage and ischaemic infarction with haemorrhagic transformation, as the latter will show high signal around the haemorrhage on DWI with corresponding low signal on ADC map due to reduced diffusion differentiating it from high signal caused by oedema surrounding primary haemorrhage.

There are studies that reported a false negative rate exists with early DWI scans of posterior circulation ischemic infarcts imaged within 24 hours mainly brain stem lacunar infarcts (Oppenheim et al., 2000; Chelala et al., 2007). The difference between this and our result of no false-negative early DWI findings can be explained by the difference in studies' design. First, the sample size of these studies was large (e.g., 356 patients in Chelala et al. (2007), study) so a larger number of brain stem infarcts were encountered. Second, they did follow up MRI of all initial negative DWI cases, which detected the ischemic lesions that were absent on the initial DWI. Similarly, Chelala et al. (2007) reported high sensitivity and specificity of DWI for acute ischemic infarcts detection, $83 \%$, and $96 \%$ respectively.

In our audit, we were able to image $68 \%$ (60 of 87 ) of the suspected recent stroke patients with DW MRI within 48 hours and 39 patients (45\%) within 24 hours of onset of symptoms; this indicates that MRI is a feasible and an increasingly preferred imaging tool for clinicians.

A limitation of our study is that we were only able to image about $15 \%$ (13 of 87 patients) within 6 hours of onset of symptoms. Many factors we think contributed to the lower number of patients imaged under 6 hours span including delay in patients' presentation to the hospital, especially elderly patients with a previous stroke, and delays in referrals to imaging. The entire process from recognition of symptoms to imaging needs to be improved to achieve best practice standards according to Guidelines for the Early Management of $\mathrm{Pa}-$ tients with Acute Ischemic Stroke (Jauch et al., 2013; Powers et al., 2019).

\section{CONCLUSION}

In conclusion, this analysis suggests high sensitivity of DWI in the diagnosis of acute \& subacute cerebral ischemic infarction, DWI proved superior to FLAIR and T2-w imaging in early detection of ischemic lesions in the first six hours from stroke onset and in cases of acute lacunar infarcts with pre-existing ischemic brain insult. The analysis also suggests that DW MRI is both feasible and accessible as a first-line neuroimaging in clinically suspected recent stroke patients.

\section{ACKNOWLEDGEMENT}

There was no financial support for this study nor any conflict of interest. I would like to thank Dr. Wael M. Gabrel, Associate Professor of Business Administration, Faculty of Economics, Omar Al-Mukhtar University and Director of Research and Scientific Studies' Office for his assistance in statistical analysis.

\section{REFERENCES}

Allen, L. M., Hasso, A. N., Handwerker, J., \& Farid, H. (2012). Sequence-specific MR Imaging Findings That Are Useful in Dating Ischemic Stroke. RadioGraphics, 32(5), 1285-1297. DOI: https://doi.org/10.1148/rg.325115760

Augustin, M., Bammer, R., Simbrunner, J., Stollberger, R., Hartung, H. P., \& Fazekas, F. (2000). Diffusion-weighted imaging of patients with subacute cerebral ischemia: comparison with conventional and contrast-enhanced MR imaging. American Journal of Neuroradiology, 21(9), 1596-1602. Retrieved from http://www.ajnr.org/content/21/9/1596.1 ong

Chalela, J. A., Kidwell, C. S., Nentwich, L. M., Luby, M., Butman, J. A., Demchuk, A. 
M., . . . Warach, S. (2007). Magnetic resonance imaging and computed tomography in emergency assessment of patients with suspected acute stroke: a prospective comparison. Lancet (London, England), 369(9558), 293-298. doi:10.1016/S0140-6736(07)60151-2

Choi, S. H., Na, D. L., Chung, C. S., Lee, K. H., Na, D. G., Adair, J. C. (2000). Diffusion-weighted MRI in vascular dementia, Neurology, 54(1), 83-89. DOI: 10.1212/WNL.54.1.83

Fiebach, J. B., Schellinger, P. D., Jansen, O., Meyer, M., Wilde, P., Bender, J., . . . Sartor, K. (2002). CT and diffusionweighted MR imaging in randomized order: diffusion-weighted imaging results in higher accuracy and lower interrater variability in the diagnosis of hyperacute ischemic stroke. Stroke, 33(9), 2206-2210. DOI: https://doi.org/10.1161/01.STR.000002 6864.20339.CB

Gonzalez, R. G., Schaefer, P. W., Buonanno, F. S., Schwamm, L. H., Budzik, R. F., Rordorf, G., . . . Koroshetz, W. J. (1999). Diffusion-weighted MR imaging: diagnostic accuracy in patients imaged within 6 hours of stroke symptom onset. Radiology, 210(1), 155-62. DOI: https://doi.org/10.1148/radiology.210.1. r99ja02155

Huisa, B. N., Liebeskind, D. S., Raman, R., Hao, Q., Meyer, B. C., Meyer, D. M., ... University of California, Los Angeles Stroke Investigators (2013). Diffusion-weighted imaging-fluid attenuated inversion recovery mismatch in nocturnal stroke patients with unknown time of onset. J Stroke Cerebrovasc Dis, 22(7), 972-977. doi:10.1016/j.jstrokecerebrovasdis.2012 .01 .004
Jauch, E. C., Saver, J. L., AdamsJr, H. P., Bruno, A., Connors, J. J., Demaerschalk, B. M., . . . Yonas, H. (2013). Guidelines for the Early Management of Patients With Acute Ischemic Stroke A Guideline for Healthcare Professionals From the American Heart Association/American Stroke Association. Stroke, 44(3), 870 947.

DOI: https://doi.org/10.1161/STR.0b013e318 $284056 a$

Lansberg, M. G., Norbash, A. M., Marks M. P., Tong D. C., Moseley, M. E., \& Albers, G. W. (2000). Advantages of Adding Diffusion-Weighted Magnetic Resonance Imaging to Conventional Magnetic Resonance Imaging for Evaluating Acute Stroke. Archives of neurology, 57(9), 1311-1316. doi:10.1001/archneur.57.9.1311

Lansberg, M. G., Thijs V. N., O'Brien, M. W., Ali, J. O., de Crespigny, A. J., Tong D. C., . . A Albers, G. W. (2001). Evolution of Apparent Diffusion Coefficient, Diffusion-weighted, and T2-weighted Signal Intensity of Acute Stroke. American Journal of Neuroradiology, 22(4), 637644. Retrieved from http://www.ajnr.org/content/22/4/637/ta b-article-info

Leiva-Salinas, C., \& Wintermark, M. (2010). Imaging of acute ischemic stroke. $\mathrm{Neu}$ roimaging clinics of North America, 20(4), 455-468. doi:10.1016/j.nic.2010.07.002

Maas, L. C., \& Mukherjee, P. (2005). Diffusion MRI: Overview and clinical applications in neuroradiology. Applied Radiology. Retrieved from https://appliedradiology.com/articles/dif fusion-mri-overview-and-clinicalapplications-in-neuroradiology 
Oppenheim, C., Stanescu, R., Dormont, D., Crozier, S., Marro, B., Samson, Y., . . . Marsault, C. (2000). False-negative diffusion-weighted MR findings in acute ischemic stroke. American Journal of Neuroradiology, 21(8), 1434-1440. Retrieved from http://www.ajnr.org/content/21/8/1434.1 ong

Powers, W. J., Rabinstein, A. A., Ackerson, T., Adeoye, O. M., Bambakidis, N. C., Becker, K., . . . Tirschwell, D. L. (2019). Guidelines for the Early Management of Patients With Acute Ischemic Stroke: 2019 Update to the 2018 Guidelines for the Early Management of Acute Ischemic Stroke: A Guideline for Healthcare Professionals From the American Heart Association/American Stroke Association. Stroke, 50(12), 344-418. DOI: https://doi.org/10.1161/STR.000000000 0000211

Rivers, C. S., Wardlaw, J. M., Armitage, P. A., Bastin, M. E., Carpenter, T. K., Cvoro, V., . . . Dennis, M. S. (2006). Persistent Infarct Hyperintensity on DiffusionWeighted Imaging Late After Stroke Indicates Heterogeneous, Delayed, Infarct Evolution. Stroke, 37(6), 14181423.

DOI: https://doi.org/10.1161/01.STR.000022 1294.90068.c4

Tan, P. L., King, D., Durkin, C. J., Meagher, T. M., \& Briley, D. (2006). Diffusion weighted magnetic resonance imaging for acute stroke: practical and popular. Postgraduate medical journal, 82(966), 289-292. doi:10.1136/pgmj.2005.038299

Tsiouris, A. J., Qian, J. (2017). Advanced Imaging in Acute Ischemic Stroke. Retrieved from https://www.reliasmedia.com/articles/1 41858-advanced-imaging-in-acuteischemic-stroke

Van Everdingen, K. J., van der Grond, J., Kappelle, L. J., Ramos, L. M. P., \& Mali W. P. T. M. (1998). Diffusion-Weighted Magnetic Resonance Imaging in Acute Stroke. Stroke, 29(9), 1783-1790. DOI: https://doi.org/10.1161/01.STR.29.9.17 83 


\title{
دور التصوير الموّزن بمعامل انتثار في تعزيز صور الرنين المغناطيسي في مرضى السكتة الدماغية حديثا
}

\author{
هاجر اكريم محمود الفضيل \\ قسم الأشعة التشخيصية، كلية الطب البشري، جامعة عر الدختار، البيضاء، لبييا \\ تاريخ الاستلام: 20 نوفمبر 2019 / تاريخ القبول: 14 أغسطس 2020 إن \\ https://doi.org/10.54172/mjsc.v35i2.316:Doi
}

المستخلص: السكتة الدماغية من الأسباب الثائعة لاخول المستشفيات، والتصوير في السكتة الحادة ضروري للتمييز بين السكتة

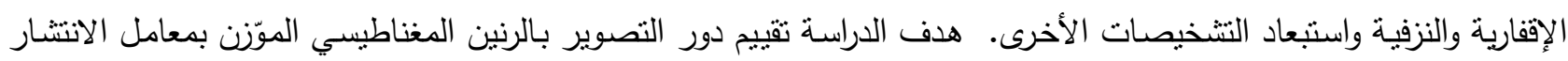

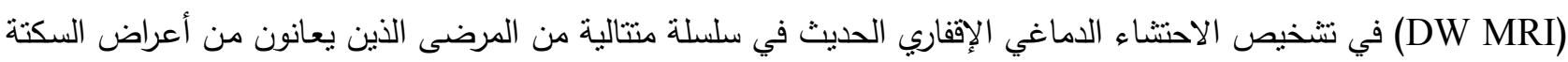

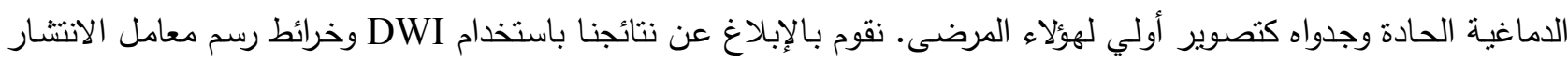

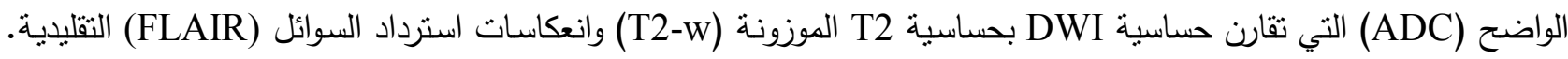

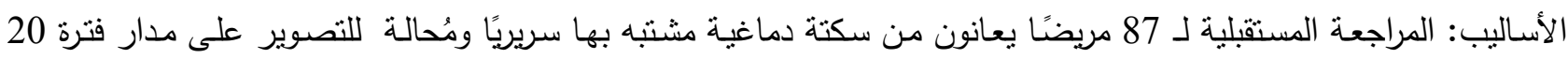

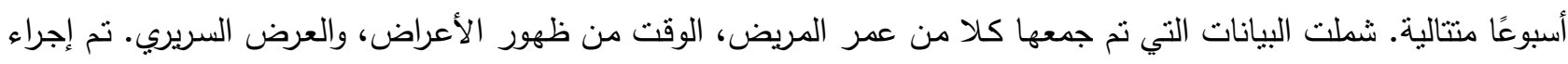

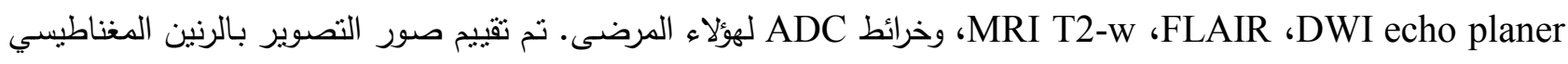

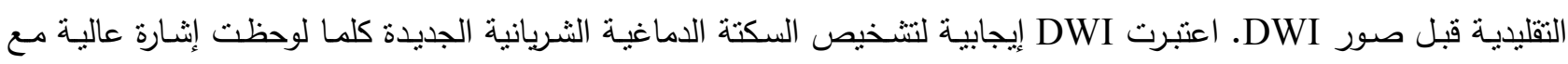

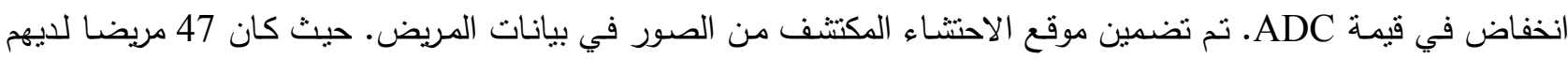

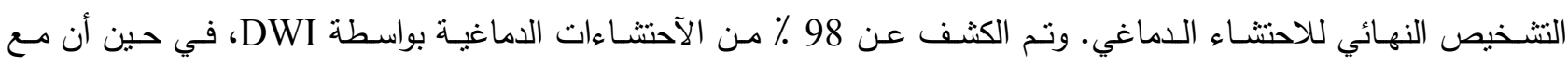

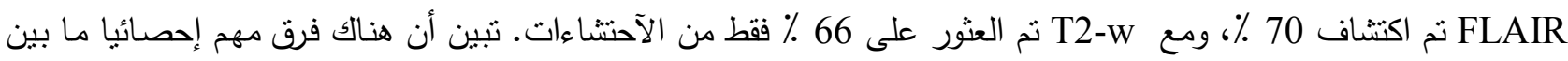

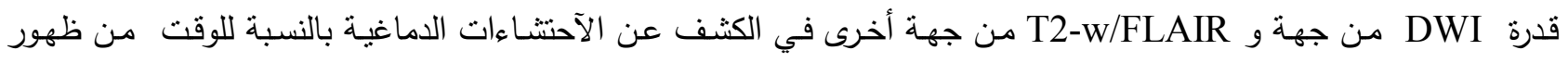

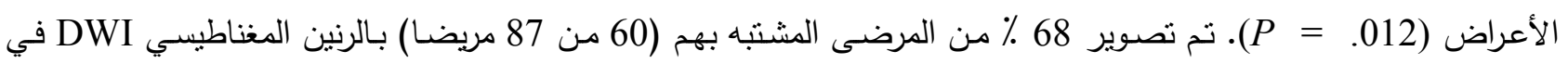

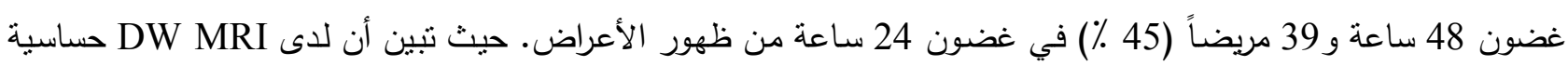
عالية وخصوصية لتتخيص احتشاء الدماغ الحاد إضافة الى كونه ممكن تماهمًا كخط تصوير أولي لهؤلاء المرضى. الكلمات المفتاحية: التصوير الموّن بمعامل الانتثار، التصوير بالرنين المغناطيسي التقليدي، T2 الموزونة، FLAIR، السكتة

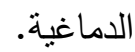

